\title{
Resistance Spot Welding of Transformation- Induced Plasticity Steel RAK 40/70
}

\section{Denis Cmorej ${ }^{1, *}$, Luboš Kaščák ${ }^{1}$}

Technical University of Košice, Faculty of Mechanical Engineering, Department of Technology, Materials and Computer-Aided Production, Mäsiarska 74, 04001 Košice

Abstract: The paper deals with the analysis of the influence of the parameters of resistance spot welding. Resistance spot welding is high-efficiency process for joining metallic materials. The application of resistance spot welding is still the most used joining method for joining the car body parts. The influence of the parameters of resistance spot welding was determined by an experiment. The optimal parameters for achieving the highest load-bearing capacity of joints for the material TRIP40 / 70 with a defined thickness of $0.77 \mathrm{~mm}$ were determined. The results of resistance spot welding joints reached the values of load-bearing capacity from $6300 \mathrm{~N}$ to 9000 $N$. The exact values parts of the experiment are shown in the paper.

Keywords: TRIP 40/70, resistant spot welding, tensile test, metallography

\section{Introduction}

One of the most important problems in the automotive industry is the safe design, lightweight of car-body parts and enhancement of crash response. For this reason, we record the increase adoption of high-strength steel sheets for specific parts of car-body members like a bumper beam, floor side reinforcement, roof bow, A-frame reinforcement and B-pillar reinforcement. Car manufactures choose steel sheets with good fatigue resistance and ability to absorb the energy of the impact. One of the most used material, with fulfilling these particular criteria are TRIP steels. TRIP steel is a particular class of high-strength steel used in the automotive industry. TRIP means "Transformation-induced plasticity". TRIP steel is known to have a perfect combination of ductility and strength. TRIP steels possess a microstructure consisting of austenite with sufficient thermodynamic instability such that transformation to martensite is achieved during loading or deformation. Many automotive TRIP steels include retained austenite within a ferrite matrix, which may also contain a hard phase (bainite and martensite) [1-7].

We know several variations of joining high-strength steels. In many cases, the material is surface treated. Because of this problem, many processes to join materials have been developed, such as mechanical joining processes (clinching and clinch-riveting) or special process of bonding. One of the best known and most used method of joining high-strength steels is resistance spot welding. Resistance spot welding is one of the best know method of joining high-strength steel sheets. Resistance spot welding as technology is highly used in the automobile industry. This process consists of generating heat using a welding current. The parameters of resistance spot welding are the welding time, welding current and the pressing force of the electrodes. These parameters affect the quality of the resulting joints [8-11].

The paper deals with the evaluation of joints created by resistance spot welding (RSW) on high-strength steel sheets TRIP 40/70with a defined thickness of $0.77 \mathrm{~mm}$. 


\section{Materials and methods}

\subsection{Resistance spot welding}

Resistance spot welding has been a valuable manufacturing process for the last decades, notably for producing vehicle bodies and enclosures. The speed, simplicity and low expense of the resistance spot welding have helped enable rapid and cost-efficient assembly of sheet metal components in various manufacturing environments. Resistance spot welding (RSW) is the process to join materials by means of pressure and heat. The heat is generated by the transient resistance (TR) of the material to electric current, which is the combination of bulk resistance (within the material) and contact resistance (material-material and electrode-material). Electrodes made of copper alloys are used to conduct the electric current and to pressure the welded materials. When an electric current passes at the contact point, the heat is generated by the welded material, putting an electrical resistance [12-14]. This heat melts the materials at the faying interface, and they are concurrently welded (the process of resistance spot welding is shown in Figure 1).
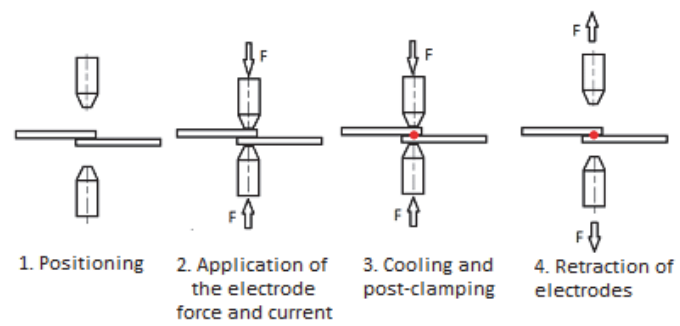

Figure 1: The principle of the resistance spot welding

A BPK 20 spot welder was used for sheet metal welding (see Figure 2.). The BPK 20 pneumatic spot welder welds materials (to thicknesses of $5 \mathrm{~mm}$ ) and allows changing the required welding parameters (welding electrode pressure, welding times and welding current).

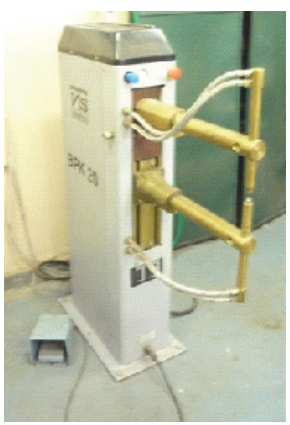

Figure 2: BPK 20 (resistance spot welder)
Electrodes (material - CuCr (A2 /1)) according to the ON 423039.71 standards were used for the welding process. The diameter of the contact surface of the electrode was $d=\varnothing 5 \mathrm{~mm}$. The parameters (recommended by the International Welding Institute) were used in the selection of spot welding parameters.

Welding was performed at a pressing force $\mathrm{Fz}=$ $4 \mathrm{kN}$, with a welding time of 12 periods on a given spot welder. The welding current was different (in the range of 4.5 to $8 \mathrm{kA}$ ) for each set of samples (sample A-sample D) - see Table 1.

Table 1: Welding parameters used for TRIP40/70

\begin{tabular}{|l|l|l|l|}
\hline Sample & Fz $[\mathrm{kN}]$ & $\mathrm{t}[$ per. $(1$ per. $=0.02 \mathrm{~s})]$ & $\mathrm{I}[\mathrm{kA}]$ \\
\hline A & 4 & 12 & 4.5 \\
\hline B & 4 & 12 & 5.4 \\
\hline C & 4 & 12 & 7.2 \\
\hline D & 4 & 12 & 8 \\
\hline
\end{tabular}

\subsection{Material for experiments}

A high-strength hot-dip galvanized steel sheet TRIP 40/70 (0.77 mm thick) was used. TRIP steels are also called multiphase steels. They contain at least two different structural components (e.g. a relatively soft phase, which forms a matrix (ferrite) and allows achieving good compressibility and a hard phase to achieve a high tensile strength).

Table 2 shows the basic mechanical properties. The values of mechanical properties were determined on the basis of tensile test according to the standard STN EN ISO 6892-1. The chemical composition of the steel sheet is shown in Table 3.

Table 2: Basic mechanical properties of TRIP 40/70

\begin{tabular}{|l|l|}
\hline $\mathrm{Rp}_{0.2}(\mathrm{MPa})$ & 450 \\
\hline $\mathrm{R}_{\mathrm{m}}(\mathrm{MPa})$ & 766 \\
\hline $\mathrm{A}_{80}(\%)$ & $26 \%$ \\
\hline $\mathrm{n}_{90}$ & 0.278 \\
\hline
\end{tabular}

Table 3: Chemical composition of materials used (\%wt)

\begin{tabular}{|l|l|l|l|l|l|}
\hline Material & \multicolumn{4}{|l|}{ Chemical composition } \\
\hline \multirow{2}{*}{$\begin{array}{l}\text { TRIP 40/70 } \\
{[0.77 \mathrm{~mm}]}\end{array}$} & $\mathrm{C}$ & $\mathrm{Mn}$ & $\mathrm{Si}$ & $\mathrm{P}$ & $\mathrm{Al}$ \\
\cline { 2 - 6 } & 0.204 & 1.683 & 0.198 & 0.018 & 1.731 \\
\cline { 2 - 6 } & $\mathrm{Nb}$ & $\mathrm{Ti}$ & $\mathrm{V}$ & $\mathrm{Mo}$ & $\mathrm{Cr}$ \\
\cline { 2 - 6 } & 0.004 & 0.009 & 0.004 & 0.008 & 0.055 \\
\hline
\end{tabular}


Samples with exact dimensions $(40 \times 90 \mathrm{~mm})$ were cut from sheet metal sheets $(0.77 \mathrm{~mm}$ thick) on NTE 2000/6.3 electric shears. On these samples, after cutting, lines were marked (distance - $32 \mathrm{~mm}$ from the edge of the sheet) to indicate the location of the welds. Sample preparation for resistance spot welding (RSW) consisted of cleaning and degreasing of joined parts. The dimensions of the samples used were determined (according to DIN 50 124) see Figure 3 and Table 4.

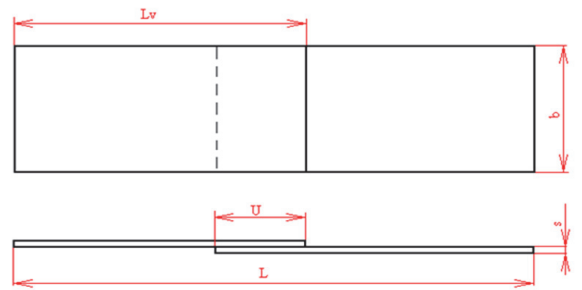

Figure 3: Sample dimensions

Table 4: Dimensions of the sample for the tensile test

\begin{tabular}{|l|l|l|l|l|}
\hline$s[\mathrm{~mm}]$ & Lv $[\mathrm{mm}]$ & $B[\mathrm{~mm}]$ & $U[\mathrm{~mm}]$ & $\mathrm{L}[\mathrm{mm}]$ \\
\hline 0.77 & 90 & 40 & 32 & 148 \\
\hline
\end{tabular}

\subsection{Tensile test}

In the experiment, the load-bearing capacity of joints was measured. A test (according to STN EN 05 1122) was used to evaluate the load-bearing capacity of joints created by resistance spot welding (RSW). The test was carried out on the TIRA test 2300 (see Figure 4).
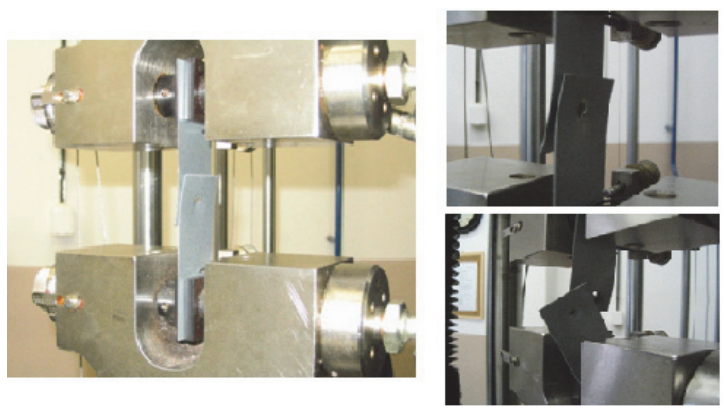

Figure 4: Sample with spot weld on TIRA test machine

\subsection{Metallographic observations of created joints}

Microscopic analysis was performed on prepared metallographic sections on a light microscope ( $\mathrm{TH}$ 4 - 200) - see Figure 5. Photo-documentation was made from the observations.

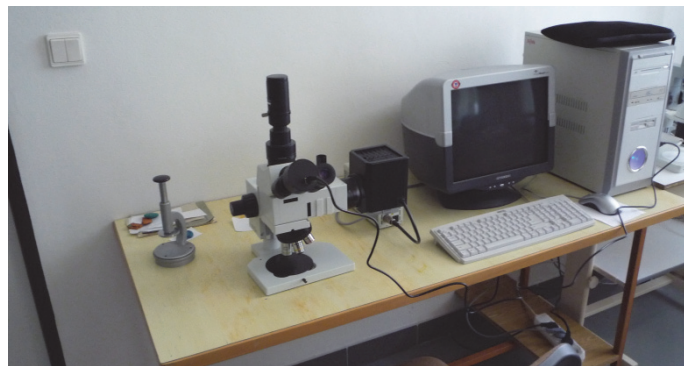

Figure 5: Microscope TH 4-200 for metallographic observation

By using light microscopy, it is possible to capture the cleanliness of the contact surfaces. We can also capture the character of the structure, the heataffected zone, the type of joint, the occurrence of various internal defects and also the exact size of the weld nugget.

\section{Analysis of Results}

\subsection{Results of tensile test}

In this part of the paper, the results of the tension test are described. The measured values of the load-bearing capacity (Fmax) are given in Table 5 . The table shows all values for the samples A, B, C, D. Figure 6 shows the samples with joints made by resistance spot welding technology. With the increasing value of the welding current (I), the imprint from the welding electrodes also changed. The imprint from the welding electrodes for each sample is shown in figure 6.

Table 5: Measured values of load-bearing capacity - Fmax

\begin{tabular}{|l|l|l|l|}
\hline Sample & Fmax [N] & Sample & Fmax [N] \\
\hline A1 & 6926 & B1 & 7733 \\
\hline A2 & 6798 & B2 & 7357 \\
\hline A3 & 7273 & B3 & 7215 \\
\hline A4 & 7176 & B4 & 7841 \\
\hline A5 & 6994 & B5 & 7295 \\
\hline Average & 7033 & Average & 7488 \\
\hline Sample & Fmax [N] & Sample & Fmax [N] \\
\hline C1 & 8986 & D1 & 8522 \\
\hline C2 & 8522 & D2 & 8035 \\
\hline C3 & 8843 & D3 & 7079 \\
\hline C4 & 8814 & D4 & 8335 \\
\hline C5 & 8432 & D5 & 8578 \\
\hline Average & 8719 & Average & 8309 \\
\hline
\end{tabular}




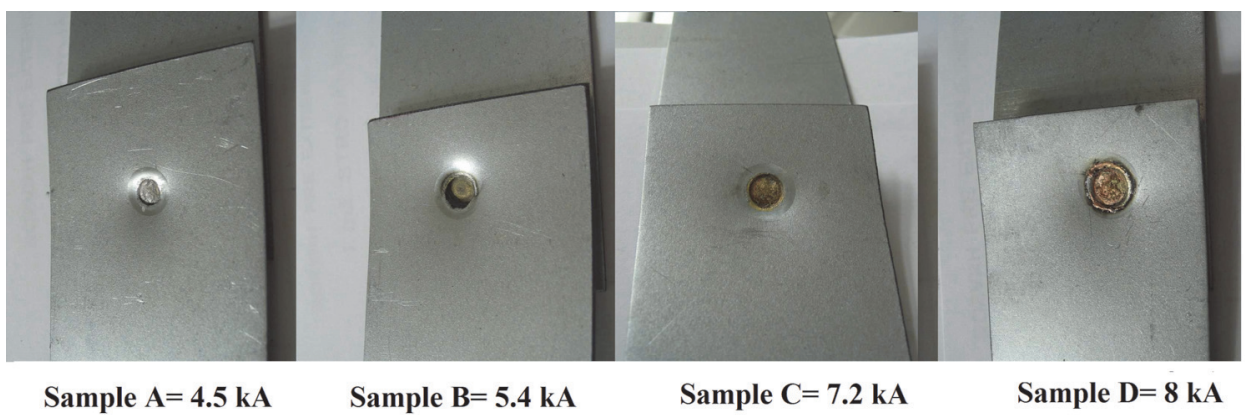

Figure 6: Samples of joints created by resistance spot welding (sample A - sample D)

The weld load-bearing capacity values Fmax ranged from $6926 \mathrm{~N}$ to $8986 \mathrm{~N}$. The average load-bearing capacity Fmax was calculated for each sample. All samples were created at the pressing force $\mathrm{Fz}=4 \mathrm{kN}$ and the welding time $t=12$ periods. The tensile test was executed under displacement control conditions on the specimen configurations in order to characterize the static behaviour of the joints and to estimate the ultimate tensile strength. Figure 7 show the average values of the force Fmax measured during the tensile test.

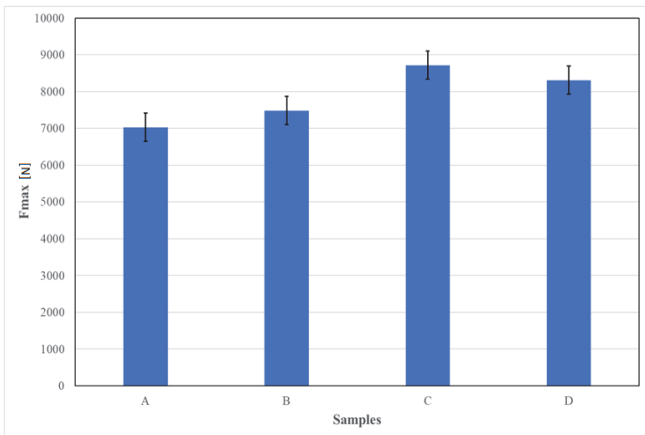

Figure 7: Graph of average values of the load-bearing capacity of joints after the tensile test for TRIP 40/70

It can be seen from the graph that the maximum value of the load-bearing capacity of the joint was reached at the welding current I $=7.2 \mathrm{kA}$. The value of the load-bearing capacity of the weld increased from the increasing value of the current up to sample $\mathrm{C}$, where the maximum load-bearing capacity was reached. In other measurements (increasing the welding current), the load-bearing capacity has already decreased. It is clear that a further increase in the welding current resulted in a decrease in the load-bearing capacity. Within the investigated parameters and in terms of load-bearing capacity of the spot weld, it is most suitable to use a welding current I $=7.2 \mathrm{kA}$. Dependency of average values of carrying capacities of welded joints Fmax on welding current (I) is shown in Figure 8.

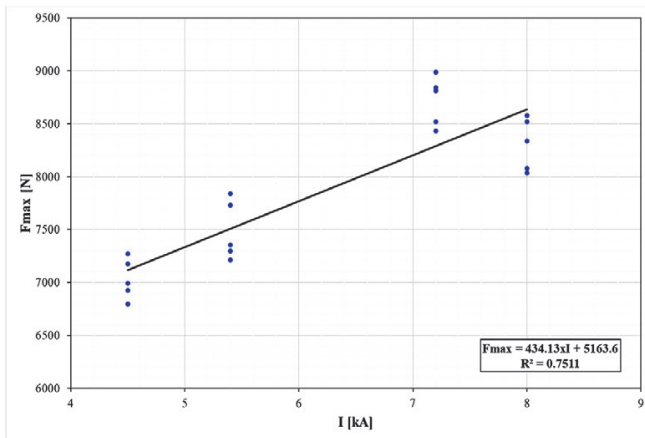

Figure 8: Dependency of average values of carrying capacities of welded joints Fmax on welding current I

\section{Metalographic Observation}

The parameters of thermomechanical processing affect the resulting microstructure of TRIP steel. In this part of the paper, the structure of the material and the structure of welded joints were investigated by means of metallographic analysis.

\section{SAMPLE A}

The material of the observed sample is TRIP 40/70. Figure 9 shows a classical fusion weld. The lowest welding current values $(11=4.5 \mathrm{kA})$ were used to create this welded joint. The lowest load-bearing capacity was also measured for these samples. No cracks or cavities were visible in the weld - see Figure 9 . Figure 10 shows the formation of a structure in the core of the weld nugget. The welded joint was formed without any pores or cracks. The sample is displayed in 200x magnification. 


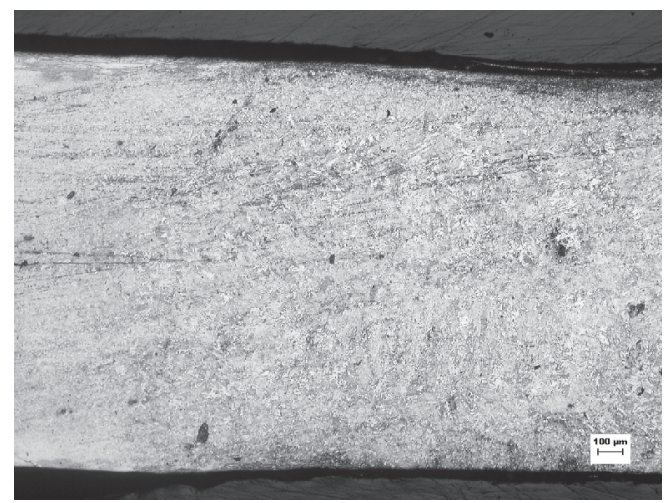

Figure 9: Microstructure of sample A
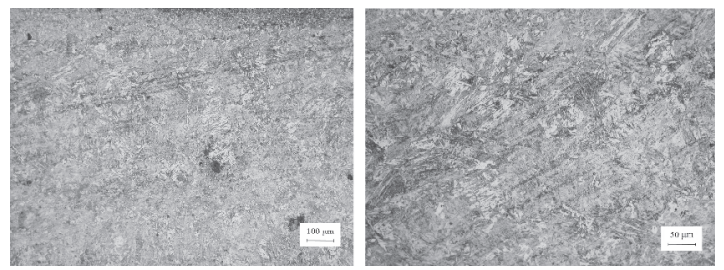

Figure 10: Microstructure of weld nugget - Sample A - 100x and 200x magnification

\section{SAMPLE B}

Higher welding current values $(I=5.4 \mathrm{kA})$ were used to make this weld joint. In figure 11, the heataffected zone is visible in the photograph of the microstructure. The heat-affected zone is more extensive than in the previous sample with a characteristic dendritic structure. The microstructure of sample B shows a classical fusion weld with characteristic areas of the base material, the heat-affected zone and the weld nugget.

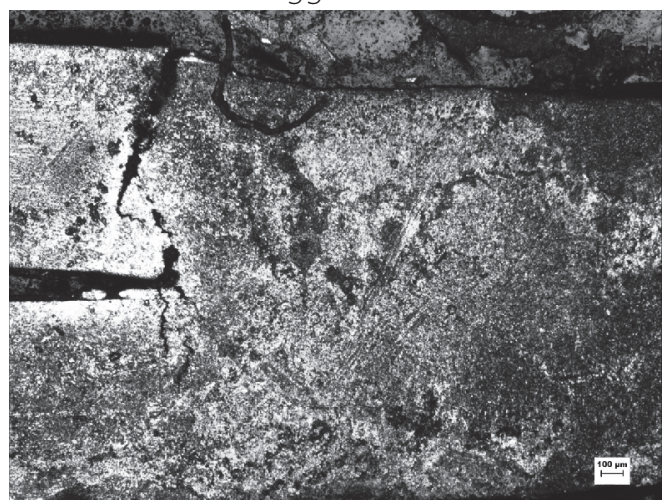

Figure 11: Microstructure of sample B

Figure 12 shows the formation of a structure in the core of the weld nugget. The welded joint was formed without any significant defect. The sample is displayed in 200x magnification.

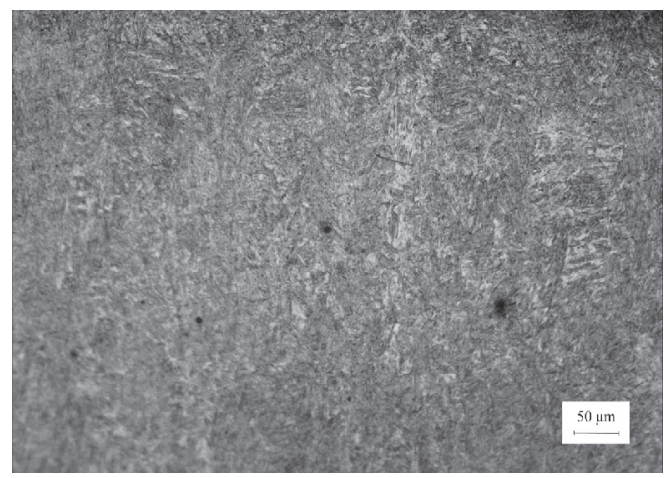

Figure 12: Microstructure of weld nugget - Sample A - 200x magnification

\section{SAMPLE C}

During the tensile tests, this joint showed the highest load-bearing capacity. Welding current $\mathrm{I}=$ $7.2 \mathrm{kA}$ were used to create the welded joint (Sample C). The microstructure of the welded joint (Figure 13) is a visible fusion welded joint without internal defects with a heat-affected zone passing into the base material. The weld nugget has a visibly pronounced coarse-grained structure.

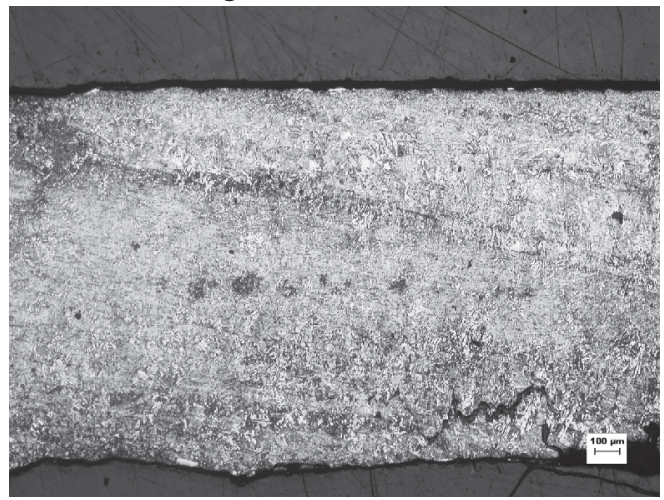

Figure 13: Microstructure of sample C

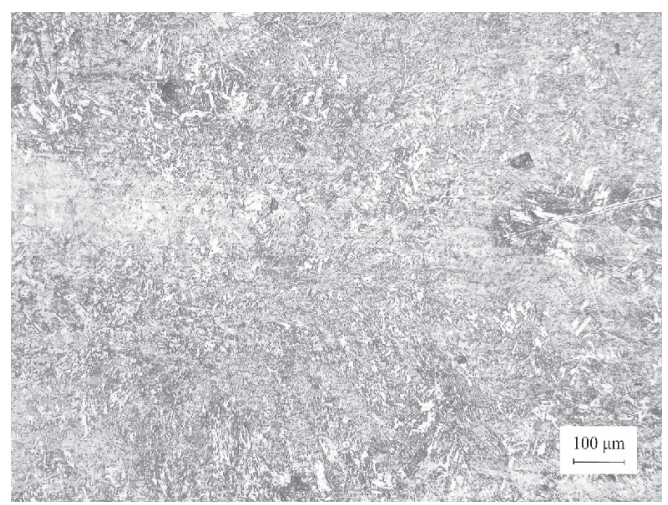

Figure 14: Microstructure of weld nugget - Sample C - 100x magnification 
Figure 14 shows the formation of a structure in the core of the weld nugget. The welded joint was formed without pores and cracks. The sample is displayed in 100x magnification.

\section{SAMPLE D}

Welding current I $=8 \mathrm{kA}$ were used to create the welded joint (Sample D). The weld nugget is high, with the heat-affected area in a relatively narrow range. Significant deformations on the surface of the joined materials can be seen.

The use of this welding current is therefore unsuitable not only in terms of the load-bearing capacity of the weld but also in terms of evaluating the microstructure of the resistance spot weld. The microstructure view of Figure 15 shows a weld with a markedly dendritic structure in the heat-affected zone.

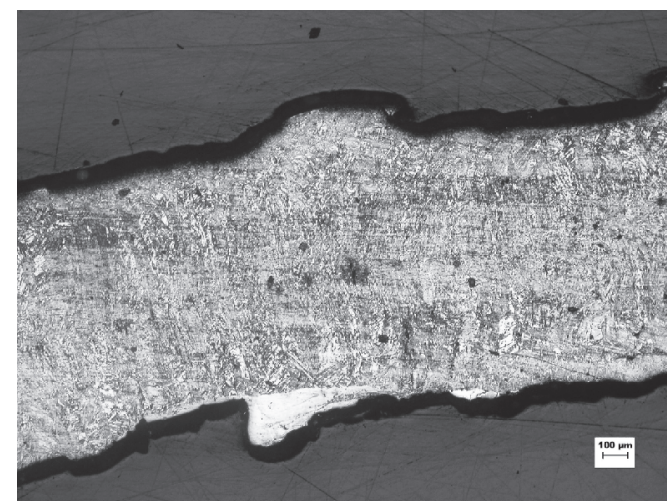

Figure 15: Microstructure of sample D

Figure 16 shows the formation of a structure in the core of the weld nugget. The cavity caused by the shrinkage of weld metal can be seen in the micrograph (Figure 15). The sample is displayed in 200x magnification.

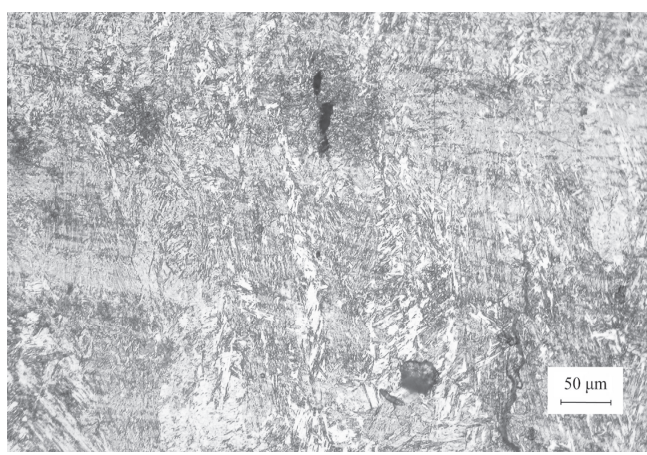

Figure 16: Microstructure of weld nugget - Sample D - 200x magnification

\section{Conclusions}

There has been a considerable increase in the use of high strength steel in automotive structures in the last few years. The real understanding of the weldability of these materials is important for successful application in future of car-body production.

In the article, the possibilities of resistance spot welding of TRIP steels were investigated. Within the paper, parameters for resistance spot welding of TRIP steels were proposed. To evaluate the properties of the resulting welded joints, a tensile test and metallographic observation were used. Due to the problems in welding high-strength steels, or their combinations with other types of materials such as non-ferrous metal sheets, it is necessary to investigate other joining methods such as mechanical joining for the further research.

Based on the results obtained from experiments, we can state:

- with increasing value of welding current - I, the value of loadbearing capacity also increased, but only up to the value of welding current I = 7.2 kA (sample C),

- further increase of the welding current above the value I $=7.2 \mathrm{kA}$ did not bring a positive effect because there was a significant decrease in the load-bearing capacity of the welded joint,

- with increasing value of the welding current, the weld nugget increased,

- at high values of welding current, the electrodes overheated, which resulted in excessive wear of the welding electrode tips, which was reflected in the surface of the weld with a significant brass layer, - within the investigated welding parameters, while the pressing force of electrodes $F=4 \mathrm{kN}$ and welding time $t=12$ periods were used, it is most efficient to use welding current I $=7.2 \mathrm{kA}$ for joining galvanized steel sheets TRIP 40/70 with the thickness of $0.77 \mathrm{~mm}$, - it is important to optimize the parameters of resistance spot welding due to the creation of the joint with optimal load-bearing capacity without specific defects situated in the joint.

\section{Acknowledgement}

This work was supported by the project APVV-17-0381 - Increasing the efficiency of forming and joining parts of hybrid car bodies and project VEGA No. 1/0259/19-Research of innovative forming and joining methods to improve the utility properties of thinwalled components.

\section{References and Notes}

1. Adamczyk, J., Grajcar A. (2005). Structure and mechanical properties of DP-type and TRIP-type sheets obtained after the thermomechanical processing. Journal of Materials Processing Technology, 162-163, 267-274. 
2. Fischer, F.D. et al. (2000). A new view on transformation induced plasticity (TRIP). International Journal of Plasticity, 16, 1937-1947.

3. Valera, J. et al. (2017). Optimization of electrical parameters in Resistance Spot Welding of dissimilar joints of microalloyed steels TRIP sheets. Procedia Manufacturing, 13, 291298.

4. Gitae, P. et al. (2020). Effects of in-situ post-weld heat treatment on the microstructure and mechanical properties of the coarse-grained heat-affected zone in a resistance spot weld in medium Mn TRIP steel. Materials Science and Engineering: A, 788, 139477.

5. Wang, W. et al. (2020). Microstructure and mechanical properties of friction stir welded joint of TRIP steel. Journal of Manufacturing Processes, 56, 623-632.

6. Vargas, V.H. et al. (2018). Characterization of resistance spot welded transformation induced plasticity (TRIP) steels with different silicon and carbon contents. Journal of Manufacturing Processes, 32, 307-317.

7. Mironov, S. et al. (2018). Microstructure and tensile behaviour of friction-stir welded TRIP steel. Materials Science and Engineering: A, 717, 26-33.

8. Biradar, A.K., Dabade B.M. (2020). Optimization of resistance spot welding process parameters in dissimilar joint of MS and ASS 304 sheets. Materials today: proceedings, 26,12841288.

9. Kaščák, L., Spišák, E., Mucha, J. (2013). Clinchrivet as an alternative method to resistance spot welding. Acta Mechanica et Automatica, 26, 79-82.

10. Watmon, T.B., Wandera, C., Apora, J. (2020). Characteristics of resistance spot welding using annular recess electrodes. Journal of Advanced Joining Processes, 2. 100035.

11. Shamsujjoha, M. et al. (2021). Mechanisms of paint bake response in resistance spot-welded first and third generation AHSS. Materialia, 15, 100975.

12. Wang, Y., Tao, W., Yang, S. (2019). A method for improving joint strength of resistance spot welds of AA 5182-O aluminium alloy. Journal of Manufacturing Processes, 45, 661-669.

13. Chabok, A., Van Der AA, E., Pei, Y. (2020). A study on the effect of chemical composition on the microstructural characteristics and mechanical performance of DP1000 resistance spot welds. Materials Science and Engineering: A, 788, 139501.

14. Bemani, M., Pouranvari, M. (2020). Microstructure and mechanical properties of dissimilar nickel-based superalloys resistance spot welds. Materials Science and Engineering: A, 773, 138825.

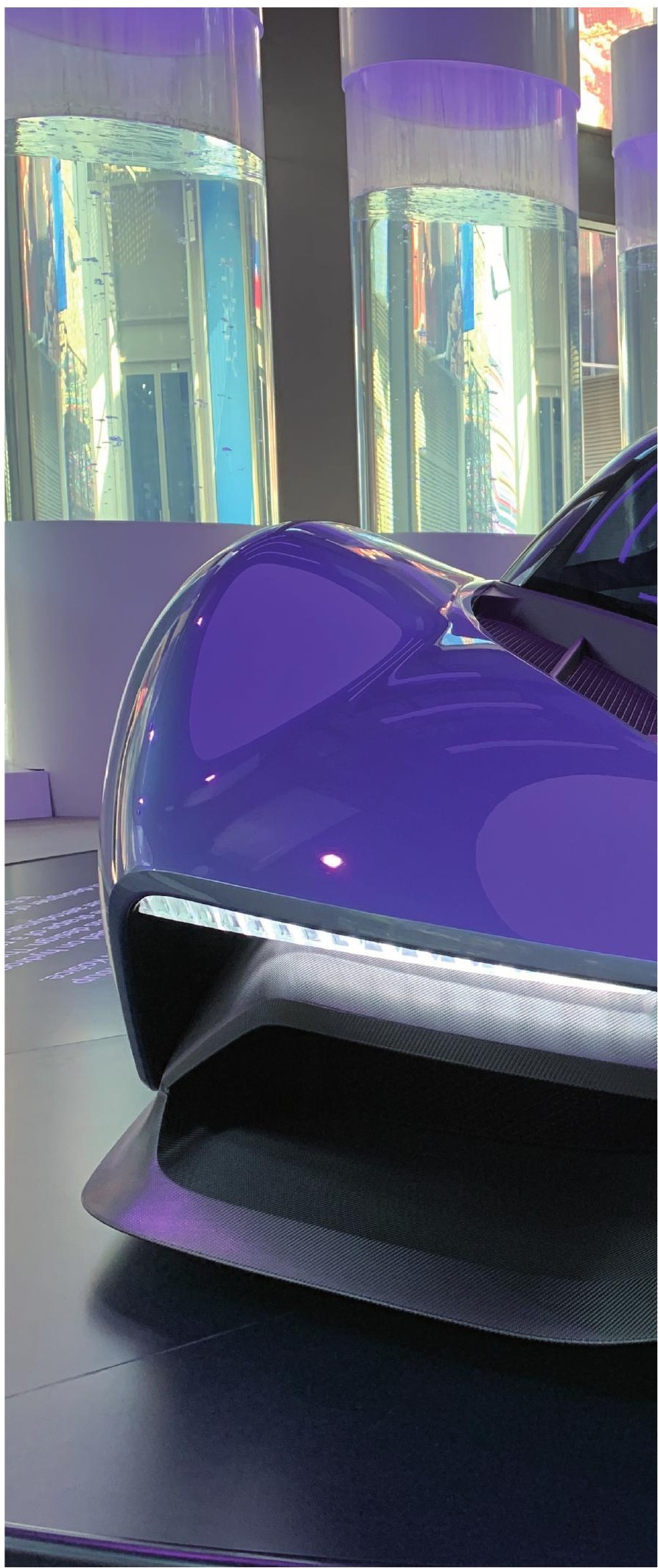

